\title{
Towards integrated pig production in the Netherlands
}

\section{L.A. DEN HARTOG}

Research Institute for Pig Husbandry, P.O. Box 83, NL 5240 AB Rosmalen, Netherlands

Received 4 October 1991; accepted 4 February 1992

\begin{abstract}
The intensive production of pigs requires attention to the effects of the production on the environment (slurry production, mineral excretion and ammonia volatilization), the quality of the product, the health and welfare of pigs, and the working circumstances of the farmer. An integrated approach to these items is necessary to achieve sustainable, safe and economic production. The constraints of integrated pork production and possible solutions are described.
\end{abstract}

Keywords: integration, husbandry, pig, environment, welfare, quality

\section{Introduction}

Pig production in the Netherlands has an annual value of about NLG 6.2 billion, which is $18 \%$ of the total production value of Dutch agriculture and horticulture. In 1990 , the total number of pigs was about 13.5 million on 29000 farms (23.8 million slaughter pigs annually). Some $70 \%$ of the pork produced is exported, either as carcasses and products or as live pigs for slaughter. Approximately $80 \%$ of the feedstuffs used is imported.

About $90 \%$ of all pigs is produced in the southeastern part of the country on farms which often have little or no arable land. This intensive production of animals is under increasing pressure of environmental regulation and legislation by government and local authorities to change to a sustainable and safe pig production. Besides, consumer and animal welfare organisations have called for husbandry systems that pay more attention to the welfare of the pigs. Consequently, both quality of the production process and quality of the product must be considered. As a result the effects on health and welfare of animals, farmers and consumers, on the environment and on the quality of the product are important items of current research. In this paper the state of disciplinary research and the constraints and perspectives for integrated pig husbandry is discussed.

\section{Group housing of sows}

The development of group housing of sows is strongly stimulated by pressure of consumer organisations and policy. There are different parameters for welfare, each 


\section{L.A. DEN HARTOG}

having its limitations (English \& Edwards, 1989). Therefore it is hard to prove whether more freedom for animals also results in more welfare. Rushen (1991) notes: 'This haste may reflect the surprising speed with which government seem prepared to pass legislation about animal welfare, so that research is essentially legislation driven'. In the Netherlands it has resulted into research on economically acceptable housing systems aimed at more animal welfare.

Barnett et al. (1989) concluded from blood corticosteroid tests that tethered shows had a reduced welfare compared to sows housed in crates or in small group-pens. Backus et al. (1991) compared the common housing systems of dry sows: girth tethering and crate housing with group housing as an alternative (Table 1). The latter included a large group of $60-70$ sows fed by two automatic feeders with electronical identification. All sows were housed individually during lactation. The number of piglets per sow year in the group housed sows was 0.4 and 1.0 lower than the tethered and crate housed sows, respectively. The percentage of culled sows per year was highest for the group housed sows. Time spent on stereotypic behaviour did not differ between the three systems. The ratio of investment for housing and equipment per dry sow place was 100,75 and 91 for crate housing, tethering and group housing, respectively. Tethered sows also had a smaller piglet production than sows housed in crates and group housed sows in an experiment of McGlone et al. (1990).

The experiment of Backus et al. (1991) shows that group housing needs further improvement. Less feeding during daytime and more feeding at night can prevent part of the aggresson. Straw bedding can reduce both aggression and leg problems (Peet, 1990). Feeding roughage to all sows at the same time facilitates checking, reduces aggression and makes the slats less slippery. Roughage can be fed especially to pregnant sows without loss of productivity (Den Hartog et al., 1988). Systems of group housing with smaller groups (7-25 animals) and simultaneous feeding are also in development.

Oestrus control is important if sows are to remain together after weaning. Nevertheless, during oestrus and service some sows may be so restless that they have to be housed individually.

Group housing of lactating sows is even more complicated than group housing of dry sows, because the needs of the piglets have also to be considered.

Table 1. Comparison of three housing systems for dry sows.

\begin{tabular}{lccc}
\hline & Crate housing & Girth tethering & Group housing \\
number of litters & 933 & 956 & 951 \\
weaners/sow/per year & 20.1 & 19.5 & 19.1 \\
\% culled sows/year & 43.7 & 53.2 & 55.6 \\
hoof lesions score $^{\mathrm{a}}$ & 4.0 & 4.0 & 6.8 \\
\hline
\end{tabular}

$1=$ excellent condition; $10=$ poor condition. 


\section{Control of aerosols}

Aerosols in pig houses may have negative effects on the health of workers (Bongers et al., 1987) and on the health and productivity of pigs (Baekbo, 1989). Current legal regulations regarding exposure to aerosols containing organic particles, including endotoxins, provide insufficient protection for the health of stockmen. Moreover, these aerosols may result in diffusion of solar radiation, contributing to the greenhouse effect in the atmosphere. Therefore, formation and concentration of aerosols in pig houses should be controlled.

Human exposure to organic aerosols can be reduced by personal protectants, such as dust filters or dust helmets. However, they are inconvenient and do not reduce the exposure of pigs nor emissions from pig houses. More ventilation is rather ineffective, as less than $50 \%$ of aerosol particles appears to be removed by ventilation (Van Wicklen \& Albright, 1987; Carpenter \& Fryer, 1990). Aerosol concentrations in pig houses with various types of feed (meal, pelleted feed or liquid feed) were lowest for liquid feeding (Zeitler et al., 1987). Besides ventilation systems (Phillips \& Thompson, 1989), composition of feed may influence aerosol concentrations (Chiba et al., 1985). Feed given to the pigs in dry form results in higher aersol concentrations than for systems where feed is given in liquid form.

To assess the effect of various control techniques, concentrations must be measured. There can be considerable spatial, diurnal and seasonal variation in concentrations, composition and size of airborne particles (Conceicao, 1989; Barber et al., 1990; Heber et al., 1988). Moreover, different measurement techniques may give different results (Adrian \& Hilliger, 1988). It is recommended to measure aerosols gravimetrically on glass-fibre filters over 24 hour periods as near to the pigs as possible (Wathes \& Randall, 1989).

Effects on human beings or pigs have to be measured indirectly by blood analysis or clinical observation of pig lungs, or even more indirectly by daily weight gain or other general parameters of long-term effects. An important question for producers is the cost-effectiveness of aerosol concentration-reducing techniques. In this sense, the technique of filtration and recirculation of air as used by Carpenter \& Fryer (1990) is effective in dust control. Further reduction of costs can be achieved by integrating aerosol control and ventilation. Other techniques, such as vacuum cleaning and weekly washing of weaned piglets with water are less effective in lowering dust concentrations. Oil is less suitable to reduce dust control, as oil drops in the air may be harmful, cause slippery floors and may render manure less attractive to arable farmers.

\section{Control of ammonia volatilization}

About $25-30 \%$ of the total deposition of acid rain in the Netherlands is caused by ammonia from animal production. From the total ammonia emission from Dutch animal husbandry, $29 \%$ originates from the pigs (18\% upon application of slurry and $11 \%$ from pig houses and slurry storages). The government has stated that the ammonia emissions have to be reduced by $70 \%$ in year 2000 compared to 1980 . 


\section{L.A. DEN HARTOG}

Ammonia $\left(\mathrm{NH}_{3}\right)$ volatilizes from urine after decomposition of urea by the urease enzyme to ammonium ions $\left(\mathrm{NH}_{4}^{+}\right)$(Doak, 1952). This process may start very soon after urination. Urea is the source of about $85 \%$ of the ammonia emitted from pig houses. The remainder comes from gradual decomposition of faeces protein. Numerous factors may influence the production of ammonia and its volatilization: separation of faeces and urine, $\mathrm{pH}$ levels, temperature, concentration, microbial processes, adsorption, purification of air, nitrification and denitrification diffusion factors such as surface of manure, time of exposure and air movement (Freney et al., 1983). Measuring techniques should consider these factors.

Ammonia may volatilize in many ways and places in a building. Recently, 54 factors were identified as relevant in measuring and reducing ammonia volatilization in pig houses. However, only flushing the slurry out of the pig house once or twice a day results in a reduction of ammonia emission by $60-70 \%$ compared to the usual slatted floor above a slurry pit. Scrapers on a very smooth floor, located under the slats, may result in a $80 \%$ reduction of the ammonia emitted. The scraper is used as a wiper. The designing of low-emission housing systems may improve the outdoors environment but may have at the same time an effect on the indoors environment.

\section{Reduction of slurry volume}

Cost of transport and agronomical value of the slurry can be improved considerably by reduction of the volume, e.g. the water content, which normally exceeds $90 \%$. Therefore, a first step is to limit the amount of water consumed by the pigs. Automatical wet-feed systems have become available with a water: feed ratio of 2:1. Drinking nipples in the dry feeders prevent of spoiling water. The water not consumed is mixed with the dry feed and consumed afterwards by the pigs. Also spoiling by water used in cleaning must be prevented, e.g. by soaking and working with an appropriate water pressure. Smooth walls in the pens need less water for cleaning. With good management in growing and finishing for pigs a dry matter content in the slurry of 9 to $13 \%$ can be realised in practice, while in breeding units it mostly is about $5 \%$.

A next step is separation of the solid and liquid parts of the slurry. The solids are preferrably transported to arable areas; the liquid fraction is rather to be spread in the area of the pig farm. However, its dose should be based on $\mathrm{N}, \mathrm{P}$ and $\mathrm{K}$ content. Slurry is usually separated mechanically. The results depend on the technique used, the dry matter content of the influent and the animal species. Sedimentation is another possiblity. Voermans \& De Kleijn (1990) reported good results with the slurry of a sow unit $(4.2 \% \mathrm{dm})$. Using polyelectrolytes, they achieved a separation of $150 \mathrm{~m}^{3}$ slurry within two days. A recent possibility is purification of the liquid fraction by reverse osmosis. In principle, the permeate can be used for cleaning the pig house. Separating the slurry under the slats is another possiblity. With this system, a solid fraction of $20-25 \% \mathrm{dm}$ can be obtained. Adding usage of straw in the pen is also possible if scrapers are mounted under the slats.

The slurry that cannot be placed on agricultural land must be processed in industrial plants. In these plants, fertilizer in the form of pellets is produced. To achieve the 
aim of the Dutch Ministry of Agriculture, Nature Management and Fisheries, 6 billion kilogram slurry must be processed yearly by 1995 .

Volume of manure production may be considerably reduced by deep litter systems, based on decomposition of manure inside the pig house (Voermans \& Huysman, 1990). These systems require a layer of $70 \mathrm{~cm}$ small woodchips in the pens, which can probably stay there for one or two years. The manure is mixed with these chips weekly and an additive with enzymes and/or bacteria is added to stimulate the process. The optimum temperature of the deep litter bed is between $40{ }^{\circ} \mathrm{C}$ and $50^{\circ} \mathrm{C}$. The perspectives of this system for Western European countries is under research. Technical, economical and ergonomic aspects are still being studied.

Another way to reduce the slurry volume is to realize a high digestibility of the feeds and a low amount of feed required per $\mathrm{kg}$ of gain. It is known that there is a large variation in feed conversion ratio and digestibility coefficients between farms (Elbers et al., 1989).

\section{Control of nutrient losses}

Because of a huge import of animal feedstuffs, the input of nutrients in the Netherlands is many times greater than the output, resulting in serious accumulation and emission of nutrients. Therefore, utilization of major nutrients, such as phosphorus $(\mathrm{P})$ and nitrogen $(\mathrm{N})$, should be increased by increasing the digestibility of the phosphorus compounds and protein in the feed. As a result, content of protein and phosphorus in the diet can be lowered. To realize this, the minimum requirements of essential amino-acids and phosphorus for pigs should be known more accurately. Phosphorus plays an important role in many metabolic functions. Phosphorus is needed for the development of skeletal tissue and protein deposition. The $\mathrm{P}$ requirement of pigs was determined for maintenance and production, and also the digestibility of $P$ in feedstuffs was determined (Jongbloed, 1987). The results were applied in a table of digestible P contents of feedstuffs for pigs. In general, the digestibility of $P$ in feedstuffs of plant origin is relatively low. For feedstuffs of animal origin, such as meat meal and milk products, the digestibility of $P$ is higher than for feedstuffs of plant origin. In feedstuffs of plan origin, $\mathrm{P}$ is present in both organic and inorganic form. The organic part consists mainly of phytate. Phosphorus from phytate can only be absorbed by the intestine after hydrolysis by phytase. Some feedstuffs like wheat and barley contain phytase. However, it is inactivated by steam pelleting above $80^{\circ} \mathrm{C}$. Since a few years a microbial phytase from Aspergillus niger is available (var. ficuum). The digestibility of $\mathrm{P}$ in pigs increases by 27-30 percentages units if this phytase is added to their diet. So, microbial phytase can play an important role in the reduction of the imbalance between input and output of $P$.

Based on the current table, the supply of digestible $P$ can be adapted to the requirement of the pig. Consequently, $\mathrm{P}$ excretion in the last few years has been lowered by about $9 \%$. After the introduction of phytase, a further reduction of the $\mathrm{P}$ excretion of about $27 \%$ can be achieved (Coppoolse et al., 1990).

There is a big difference between the utilization of $N$ and $P$. On average, the digestibility of $\mathrm{P}$ is $40 \%$, and for $\mathrm{N} 80 \%$. P utilization is increased by improving the 


\section{L.A. DEN HARTOG}

digestibility of $\mathrm{P}$ compounds. For $\mathrm{N}$, however, it is more important to reduce the urea excretion in the urine by restricting the protein content of the diet to the quantity of essential amino-acids strictly needed for maintenance and production. By reducing the current protein content in the feed by $1 \%$, the $\mathrm{N}$ excretion is reduced by about $12 \%$. However, some essential amino-acids have to be added to the feed in synthetic form. Since the introduction of the ileal digestibility of amino-acids in the Netherlands, pigs can be fed more accurately to meet their requirements (Den Hartog et al., 1989; Den Hartog, 1989). By using more kinds of feeds or by mixing feeds the requirements of the pigs can be fulfilled more precisely. Consequently, the surplus of amino-acids can be minimized and the nitrogen excretion per pig can ultimately be reduced by about $20 \%$ (Coppoolse et al., 1990).

\section{Improvement of meat quality}

During the last decade quality has been more and more comprehensively defined as the degree to which a product or process fulfils the requirements of the user. As a result, three main aspects of quality are distinguished:

- Intrinsic: composition of the product (carcass meat/fat), nutritive value, quality of meat and fat in terms of sensoric parameters (colour, flavour, taste, juiciness, etc.), and technological parameters (e.g. pH, water-binding capacity, chemical composition of fat).

- Extrinsic: hygienic parameters, such as contamination by micro-organisms and residues of contaminants and additives.

- Emotional: parameters related to health and well-being of the animals.

\section{Intrinsic quality}

Taking into account the needs of Western consumers to decrease their intake of (saturated) fat, Huiskes et al. (1989) investigated the effects of feeding on growth rate and carcass quality of pigs, especially the expression of fat on the thoracic wall and belly (FTWB). During the growing-finishing period, gilts and castrates were kept separated. They concluded that restriction in energy intake before $45 \mathrm{~kg}$ live weight had no influence on FTWB. Restriction before $25 \mathrm{~kg}$ live weight resulted in less diarrhoea problems during rearing (4\% vs $9 \%$ ) and a higher lean-meat percentage at slaughter $(52.7 \%$ vs. $51.8 \%)$. This is in agreement with data from Elsley (1963) and Campbell \& Dunkin (1983a, b). Fat content of the carcass was lower, especially in castrates, when energy intake was restricted in the last part of the growing finishing period. The fatty-acid composition in the backfat and by consequence its oxidation susceptibility are influenced by the intake of fatty acids with the diet, which is in agreement with data of Metz \& dekker (1985). It can be concluded that by a more controlled feeding program the meat: fat ratio can be influenced. 


\section{Extrinsic quality}

Extrinsic quality aspects have been investigated in a project for Integrated Quality Control (IQC) of slaughter pigs (Den Hartog et al., 1990; Elbers, 1991; Harbers, 1991). The IQC system has a dual purpose:

- to convey relevant information about medication, disease and remarks from the farm to the Meat Inspection, which is authorized to guarantee fitness for human consumption (microbiological, residues of medicines, contaminants).

- to feed-back relevant slaughterhouse data on the animals to the farmer, to improve his quality performance.

In modern industry, information from preceeding and succeeding parts of a production chain is used to maintain a high product quality. Therefore different feedback systems of slaughterhouse data on pathological-anatomical findings (PAF) of slaughter pigs in a IQC system were studied (Huiskes et al., 1990; Den Hartog et al., 1990). It was concluded from these experiments that:

- For a good feed-back of slaughterhouse data on subgroups of pigs within a herd, a reliable system of identification and registration is required.

- Most improvement during the three years of the experiment has been booked for the respiratory PAF (pleuritis and pneumonia) with a relatively high incidence $(10 \%)$. Liver lesions had a low incidence $(0.4 \%)$, but are good indicators for endoparasites.

- The producers appreciate the extra information (PAF) as a useful tool to improve their herd management. Advisors appreciate the IQC information as useful for advising activities. Feed-back should be given immediately after delivery of a batch of pigs, in a way suitable for farmers.

An IQC regulation is in development by the Product Board for Meat and Livestock, in which companies may participate on a voluntary basis. The slaughterhouse is the coordinator within a chain. In order to achieve an optimal IQC it is necessary to have a good identification and registration system. Each pig needs its own unique number. The use of injectable transponders is in development and these have to be implemented in practice in the future. The transponder is also useful in registration on farm and therefore supports the farmer's management.

\section{Emotional quality}

To improve the emotional quality, research has been started with a system of pigkeeping according the rules for so-called 'scharrelvarkens' (semi-free-range pigs). The objective for 'scharrelvarkens' is production of pig meat with more attention to animal welfare. The product is marketed as a branded meat and regulated by a special organization. The requirements for the 'scharrelvarkens' label concern housing (e.g. minimum surface area per pig, bedding), feeding (e.g. no additives), and management (e.g. minimum weaning weight and age, no teeth clipping and tail cutting). Preliminary results with growing-finishing 'scharrelvarkens' shows a substantial higher labour input of 1.3 hour per place per year compared to traditionally kept pigs. Growth rate and feed-conversion ratio were somewhat worse $(25 \mathrm{~g}$, and 
0.25 , respectively) in comparison with litter mates kept in a regular system. Carcass quality in both experimental groups was equal. However in practice, lower meat percentages were observed for 'scharrelvarkens'. Meat quality measurements showed equal intramuscular fat contents for 'scharrelvarkens' in comparison with the controls. Technological parameters $(\mathrm{pH}$, colour and water-binding capacity of fresh and heated meat) were similar for both groups (Van der Wal et al., 1989). Currently, less than $1 \%$ of the pigs are produced under this label.

Table 2. Constraints of integrated pork production and their possible solutions.

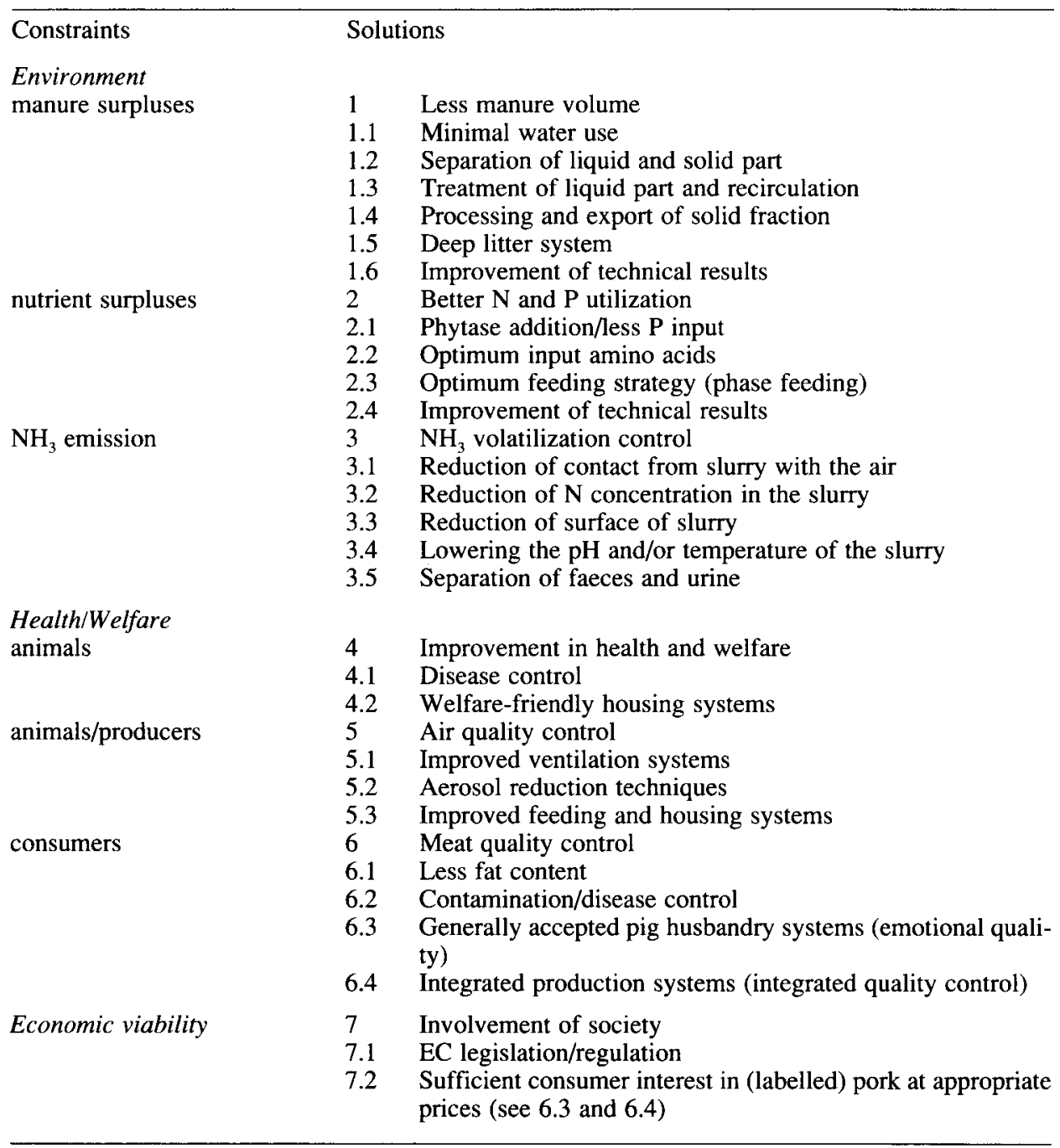


INTEGRATED PIG PRODUCTION

\section{Constraints and perspectives}

Current pig husbandry systems cannot be maintained because of their serious adverse effects on the environment. Also, the criticism by consumers of intensive pig husbandry systems has to be taken seriously. The current production systems have to be replaced as soon as possible by integrated systems with broader aims than economic output. In Table 2 , the constraints and solutions for integrated pork production system are mentioned. The Dutch pig production sector has only a limited amount of time to achieve this, in the face of increasing social and political pressure, including an ultimatum to process yearly at least $6 \%$ of the total manure production $\left(10^{8} \mathrm{t}\right)$ before 1995 . $\mathrm{NH}_{3}$ emissions have to be reduced by $70 \%$ in the year 2000 as compared to 1980 .

This urgent situation requires action for practice, education, extension and research. As described before, and mentioned in Table 2, there are technical solutions to reduce the slurry volume, the mineral excretion and ammonia emission. At this moment the solutions are in development and are being investigated separately. When the developmental stage is finished, the solutions will have to be combined. Even when the viable methods and techniques from Table 2 are introduced on the farm, there will still be a lot of farms with a slurry/mineral surplus. So slurry has to be transported to arable areas and/or processed and exported.

Research is being done on welfare-friendly housing systems. Systems with a required minimum surface area per pig, with only partly slatted floors and with the use of some bedding material may become compulsory. This may have an effect on the amount of labour required and on the working conditions. Solutions for welfarefriendly housing systems may conflict with legislation on environmental pollution and the working conditions of the farmer. Therefore an integrated approach is necessary. Not only economic but also health and welfare, working conditions, environmental pollution and productivity are criteria that have to be used in developing future systems of pig production.

The Research Institute for Pig Husbandry was started six years ago and carries out applied research in different disciplines of pig production. Therefore its contribution is to identify the constraints of integrated production systems and to develop solutions in terms of materials and methods.

\section{Acknowledgements}

The author wishes to thank J.H. Huiskes, C.E. van 't Klooster, C.M.C. van der Peet-Schwering, N. Verdoes, H.M. Vermeer and J.A.M. Voermans for their substantial contributions to this article.

\section{References}

Adrian, U. \& H.G. Hilliger, 1998. Experiences with 5 methods of dust measurements in pig houses. (In German). Tierärtzliche Umschau 43:657-664.

Backus, G.B.C., S. Bokma, Th.A. Gommers, R. de Koning, P.F.M.M. Roelofs \& H.M. Vermeer, 


\section{L.A. DEN HARTOG}

1991. Farm systems with cubicles, tethered sows and grouphousing. (In Dutch, with English summary). Research Institute for Pig Husbandry, Rosmalen, Report P1.61, 72 pp.

Baekbo, P., 1989. Air quality in pig houses. (In Danish). Institute for Internal Medicine, Veterinary and Agricultural University, Copenhagen, $161 \mathrm{pp}$.

Barber, E.M., J.R. Dawson \& V.A. Battams, 1990. Effects of sampler orientation and positioning within the building on dust measurements in a piggery. Agricultural Food and Research Council, Institute of Engineering Division Note 1573. Silsoe, $39 \mathrm{pp}$.

Barnett, J.L., P.H. Hemsworth, E.A. Newman, T.H. McCallum \& C.G. Winfield, 1989. The effect of design of tether and stall housing on some behavioural and physiological responses related to the welfare of pregnant pigs. Applied Animal Behaviour Science 24:1-12.

Bongers, P., D. Houthuys, B. Remijn, R. Brouwer \& K. Biersteker, 1987. Lung function and respiratory symptoms in pig farmers. British Journal of Industrial Medicine 44:819-823.

Campbell, R.G. \& A.C. Dunkin, 1983a. The influence of nutrition in early life on growth and development of the pig. 2. Effects of rearing method and feeding level on growth and development to $75 \mathrm{~kg}$. Animal Production 36:425-434.

Campbell, R.G. \& A.C. Dunkin, 1983b. The influence of nutrition in early life on growth and development of the pig. 3. Effects of energy intake prior and subsequent to $10 \mathrm{~kg}$ to growth and development to $30 \mathrm{~kg}$ live weight. Animal Production 36:435-443.

Carpenter, G.A. \& J.T. Fryer, 1990. Air filtration in a piggery: filter design and dust mass balance. Journal of Agricultural Engineering Research 46:171-186.

Chiba, L.I., E.R. Peo, A.J. Lewis et al., 1985. Effect of dietary fat on pig performance and dust levels in modified-open-front and environmentally regulated confinement buildings. Journal of Animal Science 61:763-781.

Conceicao, M.A.P., 1989. Spatial inhomogeneity of aerial pollutants in a poultry house. In: C.M. Wathes \& J.M. Randall (Eds), Proceedings of workshop Aerosol sampling in animal houses. EUR report 11877, Luxembourg, $141 \mathrm{pp}$.

Coppoolse, J., A.M. van Vuuren, J. Huisman, W.M.M.A. Janssen, A.W. Jongbloed, N.P. Lenis \& P.C.M. Simons, 1990. The excretion of N, P and K by farm animals, now and tomorrow. (In Dutch), DLO, Wageningen, $131 \mathrm{pp}$.

Den Hartog, L.A., 1989. The use of ileal digestible amino acids in diet formulaton for pigs. Feed Compounder 9:37-39.

Den Hartog, L.A., J. Huisman, P.A.J.H. Versteeg \& F.X. Aherne, 1988. The relevance of extra crude fibre in the diet for sows: I. Digestibility of diets with straw meal. II. Practical implication of crude fibre in sow diets. World Review of Animal Production 24:21-25.

Den Hartog, L.A., A.A.M. Kloosterman, A.T.M. Verdijk \& S.D. Duives-Cahuzak, 1990. Integrated quality control in pigs. (In Dutch). Final report Integrated Quality Control. Research Institute for Pig Husbandry, Rosmalen, $72 \mathrm{pp}$.

Den Hartog, L.A., M.W.A. Verstegen \& J. Huisman, 1989. Amino acid digestilibity in pigs as affected by diet composition. In: M. Friedman (Ed), Absorption and utilization of amino acids, Vol. 3, p. 201-206, CRC Press, Florida.

Doak, B.W., 1952. Some chemical chances in the nitrogenous constituents of urine when voided on pasture. Journal of Agricultural Science (Cambridge) 42:162-171.

Elbers, A.R.W., 1991. The use of slaughterhouse information in monitoring systems for herd health control in pigs. Doctoral Thesis, University of Utrecht, $152 \mathrm{pp}$.

Elbers, A.R.W., L.A. den Hartog, M.W.A. Verstegen \& T. Zandstra, 1989. Between and within herd variation in the digestibility of feed for growing-finishing pigs. Livestock Production Science 23:183-189.

Elsley, F.W., 1963. Studies of growth and development in the young pig. Part II. A comparison of the performance to $200 \mathrm{lb}$ of pigs reared along different growth curves to 56 days of age. Journal of Animal Science 61:243-251.

English, P.R. \& S.A. Edwards, 1989. The inter-relationship of pig welfare, pig health and economy of production. Proceedings Symposium of the European Association on Animal Production, Dublin.

Freney, J.R., J.R. Simpson \& O.T. Denmead, 1983. Volatilization of ammonia. In: J.R. Freney \& 
J.R. Simpson (Eds), Gaseous loss of nitrogen from plant - soil systems, p. 1-32. Kluwer Academic Publishers, Dordrecht.

Harbers, A.H.M., 1991. Aspects of meat inspection in an Integrated Quality Control system for slaughter pigs. Doctoral Thesis, University of Utrecht, $139 \mathrm{pp}$.

Heber, A.J., M. Stroik, J.M. Faubion \& L.H. Willard, 1988. Size distribution and identification of aerial dust particles in swine finishing buildings. Transactions of the Agricultural Society of Agricultural Engineers 31:882-887.

Huiskes, J.H., C.M.C. van der Peet-Schwering, P. Walstra, A. Jongbloed \& G. Mateman, 1989. Influence of feeding of piglets and slaughter pigs on performance and carcass quality. (In Dutch, with English summary). Report P1.34. Research Institute for Pig Husbandry, Rosmalen, $78 \mathrm{pp}$.

Huiskes, J.H., A.A.M. Kloosterman, G.H.M. Blocks, A.R.W. Elbers \& L.A. den Hartog, 1990. Different information feed-back systems for producers of slaughter pigs. Proceedings European Association on Animal Production, Toulouse, p. 1-5.

Jongbloed, A.W., 1987. Phosphorus in the feeding of pigs. Doctoral Thesis, Wageningen Agricultural University, $343 \mathrm{pp}$.

McGlone, J.J., 1990. Reproductive performance of sows over four parities in four housing systems. Annual report. Department of Animal Science, Texas Tech University, p. 67.

Metz, S.H.M. \& A.R. Dekker, 1985. Dietary fat and fat quality in growing pigs. Proceedings 36th Annual Meeting of the European Association on Animal Production, Greece, p. 1-6.

Peet, B., 1990. Housing and management in practice - straw bedded systems. In: Rast Monograph Series No. 10; Electronic Identification in Pig Production. Stoneleigh, U.K., p. 25-36.

Phillips, P.A. \& B.K. Thompson, 1989. Respirable dust in fan and naturally ventilated hog barns. Transactions of the American Society of Agricultural Engineers 32:1807-1810.

Rushen, J., 1991. Problems associated with the interpretation of physiological data in the assessment of animal welfare. Applied Animal Behaviour Science 28:381-386.

Van der Wal, P.G., J.H. Huiskes, G. Mateman \& A.H. Bolink, 1989. Carcass composition and meat quality of free-range pigs, compared to pigs kept in a traditional way. (In Dutch, with English summary). Institute for Animal Production, Zeist, Report B-322, 23pp.

Voermans, J.A.M. \& J.P.L. de Kleijn, 1990. Separation of pig slurry by separation. Proceedings of the Sixth International Symposium on Agricultural and Food Processing Wastes. American Society of Agricultural Engineers, Chicago, p. 275-278.

Voermans, J.A.M. \& C.N. Huysman, 1990. Deep litter of sawdust and shavings. Proceddings of the Sixth International Symposium on Agricultural and Food Processing Wastes. American Society of Agricultural Engineers, Chicago, p. 20-24.

Wathes, C.M. \& J.M. Randall, 1989. Proceedings Workshop Aerosol Sampling in Animal Houses. EC Report 11877, Luxembourg, 141 pp.

Wicklen, G.L. van \& L.D. Albright, 1987. Removal mechanisms for calf barn aerosol particles. Transactions of the American Society of Agricultural Engineers 30:1758-1763.

Zeitler, H.M., M. König \& W. Groth, 1987. The effect of type of feed and season on the concentration and size of dust particles. (In German). Deutsche Tierärtzliche Wochenschrift 94:420-424. 